\title{
Características do Bullying na Percepção de Alunos e Professores de uma Escola de Ensino Fundamental
}

\author{
Mariana Michelena Santos \\ Florianópolis, Santa Catarina, Brasil \\ Nádia Kienen ${ }^{1}$ \\ Departamento de Psicologia Geral e Análise do Comportamento \\ da Universidade Estadual de Londrina, Londrina, Paraná, Brasil
}

\begin{abstract}
Resumo
O presente estudo visa analisar a percepção de alunos e professores do ensino fundamental acerca das características do bullying nas escolas. A amostra foi composta por 83 alunos e seis professores de uma escola da rede pública de ensino da região da Grande Florianópolis. Para a coleta de dados foram utilizados dois instrumentos: um questionário e um roteiro de entrevista semiestruturada. Os dados obtidos no estudo foram submetidos à análise de conteúdo e à análise estatística descritiva. Dentre os resultados encontrados, pode-se afirmar que $94 \%$ dos estudantes e todos os professores entrevistados já presenciaram situações de bullying na escola. Tanto estudantes quanto professores apresentam uma definição restrita do conceito de bullying e as práticas diretas são identificadas com mais facilidade por alunos e professores do que as práticas indiretas. Para os alunos, o local de maior incidência do fenômeno é a rua, seguido do pátio e da sala de aula. Já os professores identificaram a sala de aula e o pátio como locais mais frequentes de ocorrência desse fenômeno. No que tange às características dos autores de bullying, os pesquisados indicaram que costumam ser de ambos os sexos e mais velhos do que as suas vítimas. Os resultados indicam a necessidade de refletir acerca da implementação de programas preventivos nas escolas que visem informar e instrumentalizar a comunidade escolar sobre o bullying. Tais programas podem auxiliar na redução da ocorrência de comportamentos agressivos e na promoção de um ambiente sadio de desenvolvimento e aprendizagem.
\end{abstract}

Palavras-chave: Bullying, violência, escola.

\section{Teachers and Students Perceptions of Bullying's Characteristics in a Elementary School}

\begin{abstract}
This study aims to analyze the perception of students and school teachers about the characteristics of bullying in schools. The sample was composed of 83 students and six teachers of a public school education in the region of Florianópolis. Two instruments have been used for data collection: a questionnaire and a semi-structured interview guide. The data obtained in the study were subjected to content analysis and descriptive statistical analysis. Among the findings it could be stated that: $94 \%$ of all students and teachers interviewed had witnessed some situations of bullying in school. Both students and teachers have a narrow definition of the concept of bullying and direct practices are more easily identified by students

Endereço para correspondência: Departamento de Psicologia Geral e Análise do Comportamento, Centro de Ciências Biológicas, Universidade Estadual de Londrina, Campus Universitário, Caixa Postal: 10011, Londrina, PR, Brasil 86057-970. E-mail: nadiakienen@gmail.com e mariana_michelena@msn.com Trabalho financiado pelo Programa Unisul de Iniciação Científica (PUIC).
\end{abstract}


and teachers than the indirect practices. For students, the site of highest incidence of this phenomenon is the street, followed by the patio and in the classroom. Already teachers identified classroom and patio as most frequent sites of occurrence. Regarding the characteristics of bullies, respondents indicated that they tend to be of both sexes and older than their victims. The results indicate the need to reflect on the implementation of preventive programs in schools that aim to inform and equip the school community about bullying. Such programs can help reduce the occurrence of aggressive behavior and promote a healthy learning process.

Keywords: Bullying, violence, school.

\section{Caracteristicas de Bullying en la Percepción de Alumnos y Profesores de una Escuela de Enseñanza Primaria}

\section{Resumen}

Este estudio tiene como objetivo analizar la percepción de estudiantes y profesores de la educación básica acerca de las características del acoso escolar. La muestra fue compuesta por 83 estudiantes y 6 maestros de educación pública en la región de Florianópolis. Para la recolección de datos se utilizaron dos instrumentos: un cuestionario y una entrevista semi-estructurada. Los datos obtenidos en el estudio se sometieron a análisis de contenido y análisis de estadística descriptiva. Entre los resultados, se puede afirmar que el $94 \%$ de todos los estudiantes y los profesores entrevistados había presenciado situaciones de acoso escolar en la escuela. Tanto los estudiantes como los profesores tienen una definición limitada del concepto de acoso escolar, siendo que las prácticas directas son más fácilmente identificadas por los estudiantes y los profesores que las prácticas indirectas. Para los estudiantes, el lugar de mayor incidencia de este fenómeno es la calle, seguido por el patio y el aula. Ya los maestros identificaron aula y patio como la mayoría de los sitios frecuentes de ocurrencia. En cuanto a las características de los agresores, los encuestados indicaron que tienden a ser de ambos sexos y mayores que sus víctimas. Los resultados indican la necesidad de reflexionar sobre la aplicación de programas de prevención en las escuelas, destinados a informar e exhortar a la comunidad escolar acerca de la intimidación. Estos programas pueden ayudar a reducir la ocurrencia de conductas agresivas y promover un ambiente sano para el desarrollo y el aprendizaje.

Palabras clave: Intimidación, acoso, violencia, escuela.

A violência nas escolas tem sido considerada um problema de saúde pública (Fante \& Pedra, 2008; Krug, Dahlberg, Mercy, Zwi, \& Lozano, 2002; Malta et al., 2010). O ambiente pedagógico deveria se constituir como um espaço seguro e saudável de ensino e aprendizagem, onde crianças e jovens aprendem a conviver socialmente, respeitando os outros e desenvolvendo e exercitando sua individualidade e subjetividade (Duque, 2007). Contudo, muitas vezes o ambiente escolar constitui-se como um local propício para a ocorrência de comportamentos agressivos, sofrimento e medo, os quais podem ocasionar graves consequências individuais e sociais, principalmente para os jovens envolvidos
(Catini, 2004; Lisboa, Braga, \& Ebert, 2009; Lopes, 2005).

Dentre os tipos de violência ocorridos na escola, o bullying caracteriza-se por ser um fenômeno grave e complexo, origem de diversos comprometimentos físicos, psicológicos e sociais juvenis (Beane, 2010; Hamilton, Newman, Delville, \& Delville, 2008; Lopes, 2005; Nogueira, 2005; Silva, 2010). Este fenômeno compreende todas as atividades, agressivas, intencionais e repetidas, que ocorrem sem motivação evidente, adotadas por um (ou mais) estudante contra outro(s), causando dor e angústia e sendo executadas dentro de uma relação desigual de poder (Olweus, 2006). 
No que se refere às suas formas de manifestação, o bullying pode ser classificado como direto e indireto (Olweus, 2006). As ações diretas ocorrem quando as vítimas são atacadas através de agressões físicas, ofensas verbais, roubos, expressões faciais, gestos provocativos, entre outros. Já as ações indiretas compreendem atitudes tais como isolamento social, exclusão, atitudes de indiferença e difamação. Embora sejam menos discutidas no ambiente pedagógico por serem menos visíveis, as manifestações indiretas apresentam consequências tão devastadoras quanto as diretas (Catini, 2004; Crick \& Grotpeter, 1995). Em um estudo com o propósito de identificar associações entre bullying direto e indireto e indicadores de saúde psicossocial, pesquisadores concluíram que depressão e ideias suicidas são comuns entre as vítimas de bullying, sendo mais fortes para a vitimização indireta do que para a direta (Van der Wal, Wit, \& Hirasing, 2003).

As consequências para os alunos envolvidos em práticas de bullying são inúmeras. Pesquisas apontam que os alunos vítimas de bullying podem apresentar sintomas como baixo rendimento escolar, baixa autoestima, enurese, dores de cabeça e de estômago, agressividade, pânico, depressão e atos deliberados de autoagressão, os quais podem levar à morte do próprio sujeito ou de outrem (Rigby, 2003; Salmivalli, Lagerspetz, Björkqvist, Österman, \& Kaukiainen, 1996; Salmon, James, \& Smith, 1998).

Os massacres de Columbine e Virgínia Tech, ocorridos nos Estados Unidos, podem ser mencionados como casos extremos desse tipo de violência. Em ambos, adolescentes americanos vítimas de bullying atiraram com arma de fogo contra colegas e professores, culminando na morte de dezenas de pessoas e no suicídio dos jovens atiradores (Vieira, Mendes, \& Guimarães, 2009). Fato semelhante ocorreu no Brasil em 2003, quando um estudante que sofria bullying desde a infância voltou à escola e atirou contra os ex-colegas. Depois de ferir sete pessoas, ele se matou (Veiga, 2004). Em casos extremos, ideias suicidas são recorrentes entre as vítimas (Catini, 2004).

Os autores de bullying (denominados agressores) também podem sofrer decorrências da violência praticada. Pesquisas indicam que os alunos que costumam praticar o bullying na infância tendem a sofrer de níveis mais elevados de depressão e de desordens emocionais e comportamentais (Van der Wal et al., 2003), além de se envolver em atitudes delinquentes e criminosas ao longo da vida (Olweus, 2006; Rigby, 2003; Stattin \& Magnusson, 1989; Van der Wal et al., 2003; Zaine, Reis, \& Padovani, 2010).

Justamente pela repercussão das consequências e dos efeitos negativos das práticas de bullying para o desenvolvimento e para a saúde mental dos envolvidos e do público em geral, começou-se a explorar o estudo do fenômeno nas últimas décadas (Carvalhosa, Lima, \& Matos, 2001; Lisboa et al., 2009). Pesquisas apontam que os estudos acerca da temática datam da década de 1980 (Cubas, 2006; Fischer, 2010; Silva, 2010). No Brasil, especificamente, esse tipo de fenômeno começou a ser estudado a partir de 2000 (Lisboa et al., 2009). Entretanto, isto não significa dizer que se trata de um fenômeno novo. A violência entre jovens nas escolas é um fenômeno antigo que assola o ambiente escolar, embora a terminologia utilizada para denominá-la seja atual (Fischer, 2010; Olweus, 2006).

O termo inglês bullying foi adotado universalmente devido à dificuldade de traduzi-lo para diversas línguas (Cubas, 2006; Fante \& Pedra, 2008; Flores, 2007; Lopes, 2005; Wendt, Campos, \& Lisboa, 2010). Em um estudo realizado por Smith, Cowie, Olafsson e Liefooghe (2002), os autores buscaram identificar os termos utilizados por jovens para definir bullying em diferentes culturas. Os resultados apontaram uma diversidade de palavras atribuídas ao vocábulo bullying, as quais abarcam uma variedade de enfoques e conotações. Em algumas culturas, as palavras referidas envolvem aspectos voltados à agressividade relacional e a manifestações de manipulação social e violência simbólica, enquanto que, em outras, enfatizam-se os aspectos físicos e diretos da agressão. Em português, muitas palavras são utilizadas como sinônimos de bullying, tais como maus-tratos, agressividade, intimidação, vitimização, violência entre pares e agressividade (Francisco \& Libório, 2009; Lisboa et al., 2009). Entretanto, nenhum destes si- 
nônimos contempla o significado abarcado pelo vocábulo bullying, em decorrência da multiplicidade de ações englobadas pelo conceito (Lisboa, 2005; Wendt et al., 2010), o que remete à manutenção do seu uso no Brasil.

Em estudo que objetivou investigar as características dos atos agressivos ocorridos entre crianças do município do Rio de Janeiro, os pesquisadores identificaram que $40 \%$ dos alunos admitiram ter tido algum tipo de envolvimento na prática de bullying, como alvo e/ou como autor (Lopes, Monteiro, \& Saavedra, n.d.). Dos alunos pesquisados, $69 \%$ admitiram não saber as razões que levam à ocorrência de bullying ou consideraram tratar-se de uma forma de brincadeira e $51 \%$ afirmaram que não receberam nenhum tipo de orientação ou advertência quanto à incorreção de seus atos. Estes dados denunciam a falta de informação e orientação das crianças a respeito desta prática de violência e a falta de preparo dos professores neste contexto.

Outrossim, pesquisas em âmbito nacional apontam que os atos de violência entre alunos costumam ocorrer com maior frequência na sala de aula e no pátio do recreio, espaços escolares nos quais o controle da violência entre alunos deveria ser mais eficiente por parte de professores e funcionários (Fante \& Pedra, 2008; Fischer, 2010; Francisco \& Libório, 2009; Lopes, 2005). Da mesma forma, estudos indicam a relevância da intervenção da comunidade escolar sobre o bullying como forma de interromper a ocorrência desse tipo de fenômeno (Catini, 2004; Fekkes, Pijpers, \& Verloove-Vanhorick, 2005; Lisboa et al., 2009; Lobato \& Placco, 2007). Deste modo, investigar também a percepção de professores acerca do bullying nas escolas é de extrema relevância, visto que esses são profissionais que poderiam intervir de modo mais efetivo sobre esse tipo de fenômeno, desde que estejam preparados para tal.

Pesquisas apontam que o índice de alunos que presenciam e/ou se envolvem em práticas de bullying vem aumentando (Fante \& Pedra, 2008; McLaughlin \& Miller, 2008). No Brasil, investigações que contemplam diferentes regiões do país vêm sendo realizadas com o intuito de mapear as características e a frequência do bullying nas escolas em âmbito nacional. Dentre estas, situa-se uma pesquisa cujo propósito foi identificar situações de violência entre pares e de bullying nas escolas brasileiras a partir de um levantamento nas cinco regiões geográficas do país (Fischer, 2010). Os resultados apontaram que $70 \%$ da amostra de estudantes havia presenciado cenas de agressões entre colegas, sendo que $30 \%$ haviam vivenciado ao menos uma situação violenta neste mesmo período. Além disso, 10\% dos estudantes pesquisados afirmaram ter praticado e sofrido violência entre colegas da escola numa frequência superior a três vezes durante o ano letivo pesquisado. De acordo com a autora, os alunos, pais, responsáveis e equipe escolar que compuseram a amostra praticamente desconheciam a terminologia bullying. No entanto, suas práticas eram reconhecidas e associadas a episódios de maus-tratos na escola, fenômeno presente e conhecido por todos (Fischer, 2010).

Somando-se a estes achados, outro estudo foi realizado no Brasil no decorrer de 2009, constituindo-se como o primeiro levantamento sobre bullying com dados de todas as capitais do país. Os resultados apontaram que 5,4\% dos alunos indicaram ter sofrido bullying quase sempre ou sempre nos últimos 30 dias; $25,4 \%$ foram raramente ou às vezes vítimas de bullying e 69,2\% não sentiram nenhuma humilhação ou provocação - bullying (Malta et al., 2010). Neste sentido, os dados apontam para a necessidade urgente da elaboração de medidas que visem reduzir e prevenir o bullying nas escolas.

Dada a incidência de bullying que tem sido identificada no contexto escolar e considerando a relevância de mapear as características desse tipo de fenômeno, no presente artigo pretende-se problematizar este tipo de violência a partir das percepções de professores e de alunos de uma escola de ensino fundamental. A análise destes diferentes olhares visa auxiliar na sistematização do conceito de bullying, além de instrumentalizar os acadêmicos e profissionais deste campo de estudo para a elaboração de planos de intervenção e de efetivação dos mesmos nos ambientes pedagógicos brasileiros. 


\section{Método}

\section{Participantes}

Trata-se de uma pesquisa descritiva delineada como survey que, segundo Gil (1999), caracteriza-se pela interrogação direta das pessoas cujo comportamento se deseja conhecer, por meio da solicitação de informações a um grupo significativo para caracterizar sua percepção acerca de um fenômeno. Participaram do estudo 83 alunos de quinta a oitava série do ensino fundamental e seis professores que lecionam para estas turmas em uma escola da rede pública de ensino de uma cidade localizada na região da Grande Florianópolis/SC.

Foram distribuídos 300 Termos de Consentimento Livre e Esclarecido (TCLE) aos alunos, visando à solicitação de autorização de seus responsáveis legais para que os mesmos pudessem participar da pesquisa. Desses, 83 alunos trouxeram o TCLE assinado pelos pais no dia da coleta de dados, sendo esses os alunos participantes da pesquisa. Dentre os 15 professores, foram selecionados apenas aqueles que fossem de diferentes áreas de formação (conforme classificação indicada no Conselho Nacional de Desenvolvimento Científico e Tecnológico [CNPq]), que lecionavam na escola há pelo menos um ano e que trabalhavam em turnos diferentes (matutino e vespertino). A partir desses critérios, foram selecionados seis professores.

Dentre os alunos que compuseram a amostra examinada, $67 \%$ eram do sexo feminino e $33 \%$ do sexo masculino. As idades variaram de 11 a 16 anos $(M=13 ; D P=1,31)$. Sessenta e um por cento estudavam na escola por um período maior que dois anos e $45 \%$ eram repetentes, sendo que oito deles haviam repetido de série duas ou três vezes.

No que se refere aos professores que participaram da pesquisa, três eram do sexo masculino e três do sexo feminino, com idades variando entre 28 e 45 anos $(M=36 ; D P=5,5)$. No que tange à área de formação dos professores, dois professores possuíam formação na área de "ciências humanas" e um em cada uma das seguintes áreas: "ciências biológicas", "ciências exatas", "ciências da saúde" e "linguística, letras e artes". Dos seis professores, cinco possuíam contrato de trabalho efetivo e um era admitido em caráter temporário. $\mathrm{O}$ tempo em que os mesmos atuavam na instituição variou entre um e cinco anos e o tempo de atuação como professores variou de cinco a vinte anos. Compuseram a amostra da pesquisa professores e alunos dos turnos matutino e vespertino, com a finalidade de verificar se em ambos os períodos são percebidas ocorrências de bullying por professores e alunos.

\section{Instrumentos}

Foram utilizados dois instrumentos para a realização da coleta dos dados: um questionário para o levantamento de dados acerca das características do bullying na escola com os estudantes e um roteiro de entrevista semiestruturada para a obtenção de dados referentes à percepção dos professores.

O questionário foi composto por dezesseis questões fechadas de múltipla escolha e três questões abertas, totalizando dezenove questões, as quais visavam avaliar as características do bullying na escola, as decorrências do mesmo para os envolvidos, as intervenções feitas por alunos, professores e gestão escolar e as intervenções que deveriam ser realizadas para prevenir esse tipo de fenômeno nas escolas. Neste estudo optou-se por apresentar apenas oito dessas questões, as quais dizem respeito à caracterização do bullying, haja vista a quantidade de variáveis investigadas. Dentre essas oito questões, sete eram fechadas e uma aberta. Duas dessas questões fechadas referiam-se a tipos de comportamentos considerados agressivos: uma contendo 20 categorias de comportamentos diretos e indiretos de agressividade que poderiam ser assinalados e outra contendo dezoito figuras elaboradas pelas pesquisadoras a partir de um software livre disponibilizado na rede mundial de computadores. Dentre essas dezoito figuras, oito representavam comportamentos não-agressivos e dez representavam comportamentos agressivos diretos ou indiretos, estando as mesmas distribuídas de forma aleatória. Em ambas as questões os participantes poderiam assinalar quantas alternativas desejassem. 
As demais questões fechadas referiam-se a: já terem presenciado comportamentos agressivos na escola (com alternativas de resposta: "sim" ou "não"); frequência com que esses comportamentos ocorriam (com alternativas de resposta: "uma vez", "quase toda semana", "quase todos os dias", "várias vezes ao dia" e "nunca vi"); locais de ocorrência dos comportamentos agressivos (com sete alternativas de resposta, tais como: "na rua", "no pátio da escola", "na sala de aula") e característica dos agressores (contendo alternativas referentes à idade e série em uma questão e ao gênero na outra questão).

A questão aberta referia-se à justificativa para a escolha das figuras, em que era solicitado aos participantes que escolhessem uma figura assinalada e explicassem por que consideravam que aquele comportamento era agressivo.

O roteiro de entrevista compreendia catorze questões que visavam, à semelhança do questionário, avaliar as características do bullying na escola, as decorrências do mesmo para os envolvidos, as intervenções feitas por alunos, professores e gestão escolar e as intervenções que deveriam ser realizadas para prevenir esse tipo de fenômeno nas escolas. Neste estudo foram utilizadas seis questões diretamente relacionadas à caracterização do bullying, as quais envolviam aspectos relativos a: compreensão do professor a respeito do que é bullying, tipos de comportamentos que caracterizam o bullying, locais da escola nos quais esses comportamentos ocorrem e características dos agressores e das vítimas. Essas questões foram escolhidas por tratarem diretamente da caracterização desse tipo de fenômeno na escola, possibilitando comparações entre os dados obtidos junto aos alunos e aos professores.

Os instrumentos de coleta de dados foram submetidos a um pré-teste com sujeitos que atendiam aos mesmos critérios delimitados para a escolha dos participantes da pesquisa. Através da aplicação dos pré-testes foi possível verificar a necessidade de readequar algumas questões, tanto no questionário quanto na entrevista semiestruturada. Foi percebido que a linguagem utilizada em ambos, embora simples e de fácil entendimento para o público em geral, ainda fazia-se difícil ao entendimento tanto do aluno quanto do professor. Deste modo, algumas questões foram reescritas e figuras do questionário foram alteradas antes de proceder à coleta de dados propriamente dita.

A exemplo destas alterações que se fizeram necessárias após a realização do pré-teste, optou-se por substituir o vocábulo bullying pela expressão "comportamentos agressivos entre colegas da escola" ao longo do questionário utilizado para levantar a percepção dos alunos. Observou-se que a expressão "comportamentos agressivos" foi compreendida com maior facilidade pelos alunos que compuseram a amostra, em detrimento de "bullying", "maus-tratos" e "vitimização". Conforme citado anteriormente, a terminologia inglesa ainda é pouco conhecida e tende a causar estranhamento no ambiente escolar brasileiro (Fischer, 2010). Para Smith et al. (2002), na língua portuguesa, por vezes, se faz necessária a utilização de termos mais populares e de senso comum para explicar os seus correspondentes científicos. Contudo, mesmo sem utilizar o termo bullying ao longo do questionário, foram investigados aspectos intrínsecos ao conceito, tais como a frequência com que os alunos presenciam comportamentos agressivos neste ambiente e o desequilíbrio de poder existente entre os envolvidos.

\section{Procedimentos}

Inicialmente, foi realizada uma reunião com a supervisora de educação superior da Gerência Regional de Educação (GERED), a fim de solicitar autorização para a realização da pesquisa. Após o consentimento deste órgão, através da assinatura da Declaração de Ciência e Concordância das Instituições Envolvidas, o diretor da instituição de ensino na qual seria realizada a coleta de dados também concedeu a autorização para a execução do estudo. A partir disso foram agendadas as datas para a entrega do Termo de Consentimento Livre e Esclarecido aos estudantes, com o propósito de que eles pudessem levá-lo a seus pais, assim como para a realização da coleta dos dados. O diretor da instituição também disponibilizou os números de telefone dos professores da escola para que as pesquisadoras 
pudessem contatá-los e agendar datas e horários para a realização das entrevistas.

O primeiro contato com os alunos foi realizado durante seus horários de aula, quando foram descritos os objetivos da pesquisa e distribuída uma carta de apresentação junto ao Termo de Consentimento Livre e Esclarecido que deveria ser entregue aos pais, com a finalidade de que os mesmos autorizassem os filhos a participarem do estudo. Por se tratar de uma pesquisa que envolve adolescentes, teve-se o cuidado ético de produzir uma carta endereçada aos pais, com a finalidade de explicitar-lhes os propósitos da pesquisa, a sua relevância no âmbito escolar, bem como a importância da participação dos seus filhos para a viabilização da mesma. A coleta de dados só foi realizada com os alunos que trouxeram o Termo de Consentimento Livre e Esclarecido assinado pelos pais e/ou responsáveis durante o período de aula em dias e horários previamente estabelecidos junto à direção da escola. O tempo médio da aplicação do instrumento foi de vinte e três minutos, sendo realizada coletivamente.

Com os professores foi feito, por telefone, agendamento prévio de cada entrevista. Nesse contato telefônico foram explicados os objetivos e os procedimentos metodológicos básicos da pesquisa, seguidos do convite para participação. A coleta de dados foi realizada em locais de fácil acesso aos professores, tais como a sala dos professores e a sala da orientadora pedagógica. Os professores também assinaram o Termo de Consentimento Livre e Esclarecido e o Termo de Consentimento de Gravação da Entrevista em Áudio, para a viabilização da transcrição dos dados. Cada entrevista durou em média vinte e quatro minutos. Todos os sujeitos foram orientados a respeito da participação voluntária e do sigilo garantido aos dados coletados na entrevista. Os procedimentos utilizados foram aprovados pelo Comitê de Ética em Pesquisa na Universidade do Sul de Santa Catarina, sob protocolo de número 09.435.7.07.III.

\section{Análise de Dados}

Os dados obtidos através das questões fechadas apresentadas no questionário foram ta- bulados e organizados a partir de categorias estabelecidas a priori, sendo tratados por meio de percentagem de ocorrências em relação ao total de sujeitos da amostra. As categorias a priori consideradas para a caracterização do bullying foram: tipos de comportamentos considerados agressivos; ocorrência e frequência de comportamentos agressivos na escola; locais nos quais o bullying costuma ocorrer, e características dos agressores (envolvendo aspectos referentes a idade e gênero). Já os dados obtidos por meio da gravação em áudio das entrevistas realizadas foram transcritos e submetidos à análise de conteúdo. Segundo Bardin (1977/2011), a análise de conteúdo se caracteriza por um conjunto de técnicas de análise das comunicações que, por meio de procedimentos sistemáticos e objetivos, possibilita acesso ao conteúdo das mensagens. A fim de sistematizar os dados obtidos a partir das entrevistas com os professores, foram construídas categorias de análise a posteriori, tais como: conceito, subdividida em definição, tipo de bullying, local onde ocorre, sujeitos envolvidos e desconhecimento da terminologia; tipos de bullying, subdividida em agredir diretamente e agredir indiretamente; locais onde ocorre, e características dos envolvidos, subdividida em alunos que sofrem bullying, que praticam bullying e vítimas-agressoras.

\section{Resultados}

\section{Características do Bullying, na Percepção dos Alunos}

Os resultados apontaram que $94 \%$ dos alunos afirmaram ter presenciado comportamentos agressivos ocorrendo em sua escola, $4 \%$ não responderam e $2 \%$ indicaram nunca ter presenciado tais comportamentos. A maioria (59\%) afirmou presenciar comportamentos de bullying entre colegas frequentemente (várias vezes ao dia, quase todos os dias, quase todas as semanas).

Quanto à percepção dos estudantes investigados acerca dos comportamentos de bullying quando ocorrem entre colegas da escola, pode-se concluir que comportamentos diretos, tais como chutes, socos e tapas ou agressões verbais, foram 
percebidos com maior frequência do que comportamentos caracterizados como indiretos, tais como difamar, isolar ou excluir. Conforme pode ser observado na Figura 1, foi possível perceber que, dentre as alternativas que apresentavam diferentes tipos de comportamento, o comportamento mais assinalado pelos estudantes foi "dar socos", o qual se configura como um comportamento direto de agressão, sendo identificado por $89 \%$ dos participantes. Em contrapartida, o comportamento "deixar o colega de lado", o qual se configura como um comportamento indireto, foi indicado por apenas $19 \%$ dos sujeitos investigados.

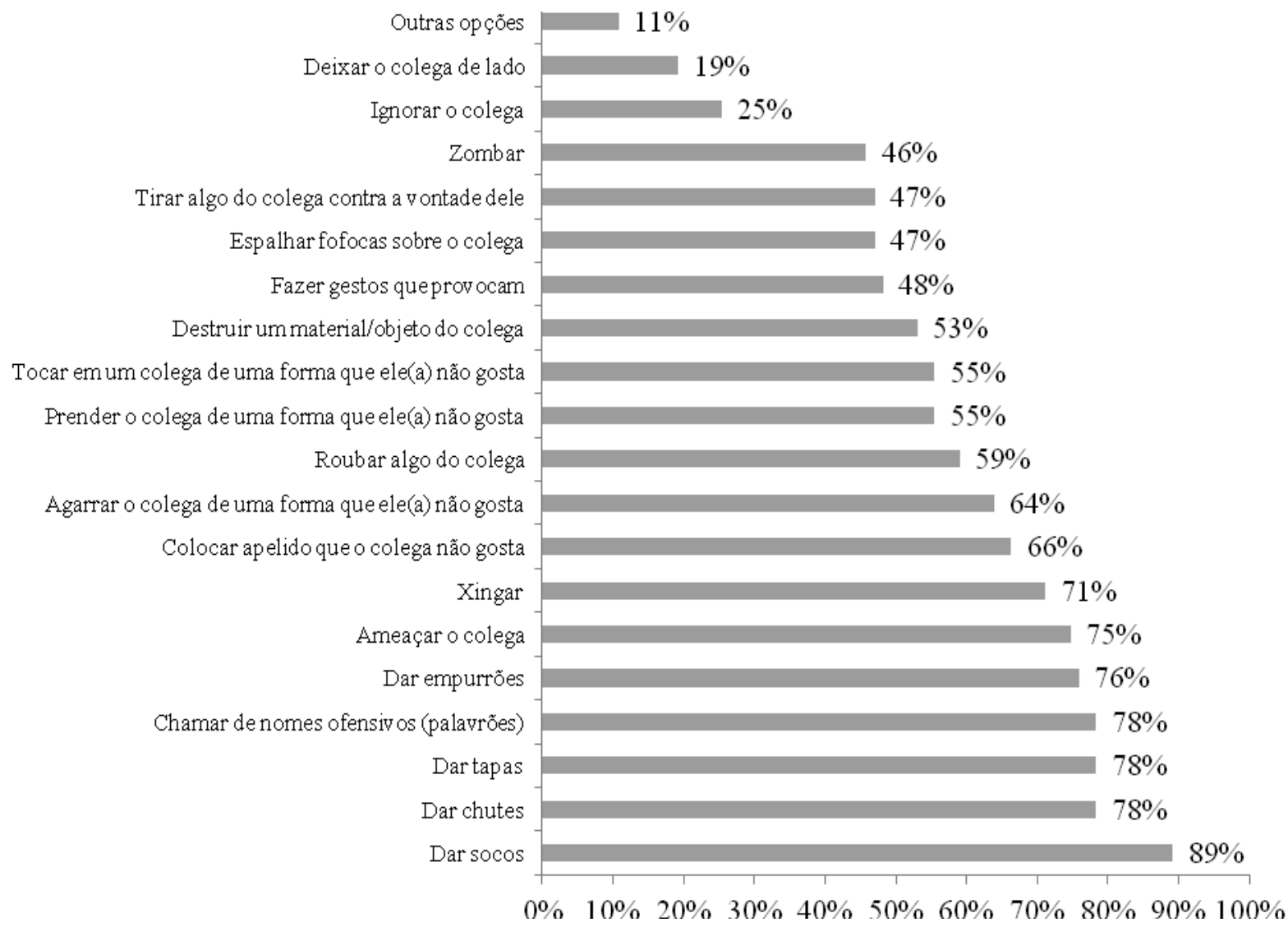

Figura 1. Comportamentos identificados como agressivos pelos estudantes quando ocorrem entre colegas da escola.

Quando foram apresentadas imagens para que os estudantes assinalassem aquelas que julgavam ilustrar comportamentos agressivos, as que representavam comportamentos considerados de agressão direta também foram identificadas com maior frequência pelos alunos que compuseram a amostra. Na Figura 2, pode ser observado que, dentre as imagens que representavam comportamentos agressivos $(\mathrm{B}, \mathrm{C}, \mathrm{E}, \mathrm{F}$, H, J, L, M, Q e R), a imagem J, a qual representava uma agressão física, foi assinalada com maior frequência pelos respondentes (96\%), enquanto a imagem $\mathrm{H}$, representando um comportamento indireto de exclusão, foi assinalada com menor frequência pelos estudantes (67\%).

Quanto aos locais onde os comportamentos de bullying entre alunos costumam ocorrer, os estudantes assinalaram com maior frequência as alternativas "na rua, indo ou voltando da escola" (70\%), "no pátio da escola" (67\%) e "na sala de aula" (61\%), conforme é possível observar na Figura 3. 


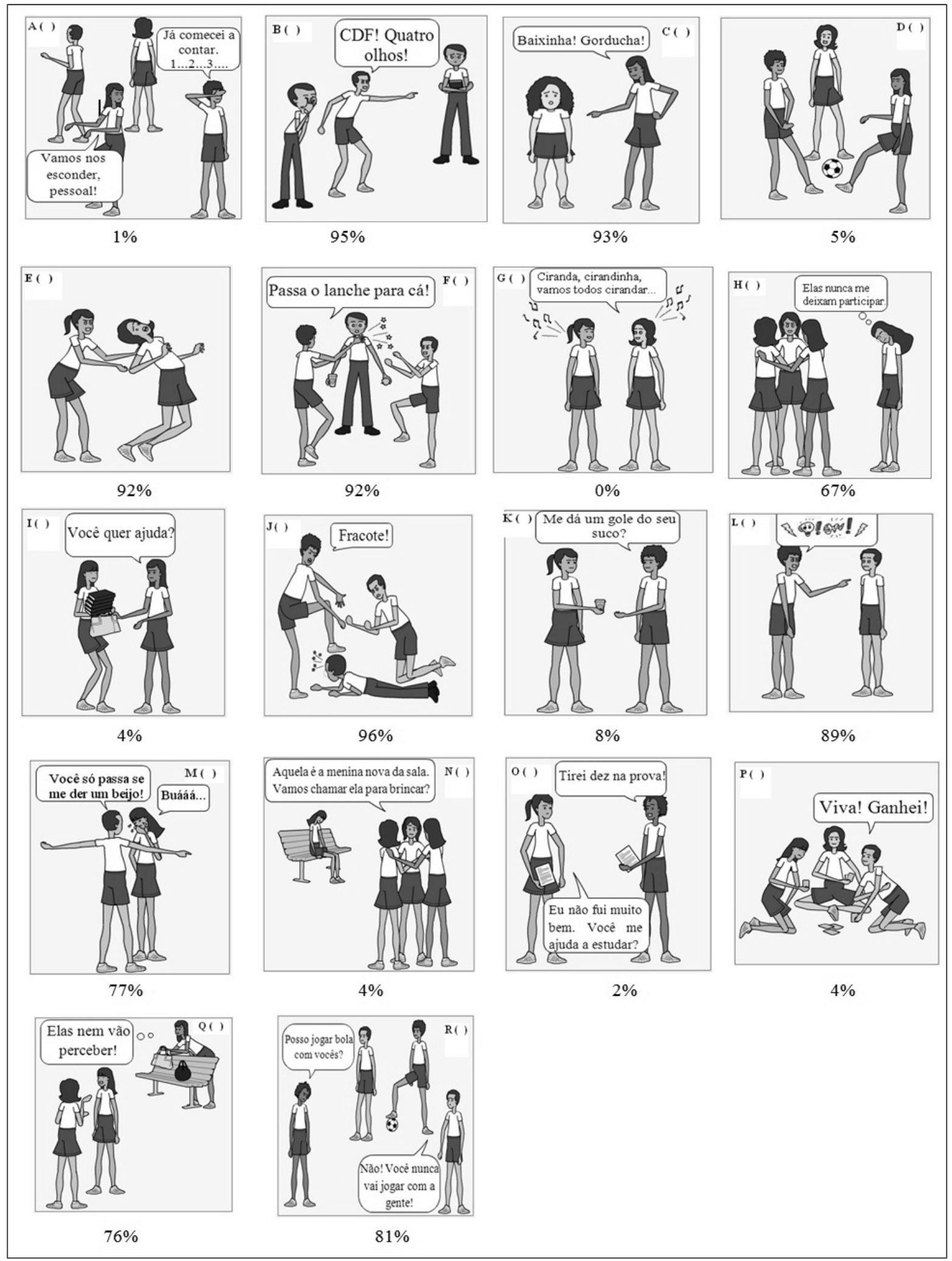

Figura 2. Imagens que ilustram comportamentos agressivos e não-agressivos e as respectivas percentagens de estudantes que as assinalaram. 


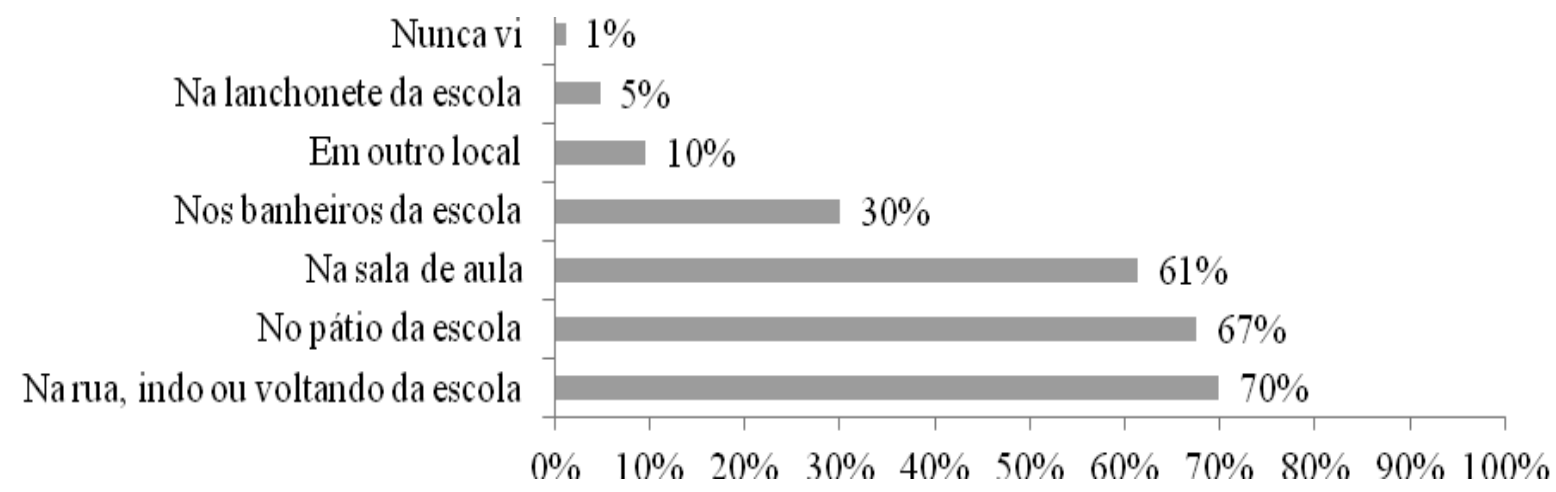

Figura 3. Locais onde costumam ocorrer os comportamentos agressivos, na percepção dos alunos.

Foram investigados junto aos alunos dois aspectos referentes às características dos colegas que costumam provocar bullying: a idade e o sexo. No que se refere à idade, não se buscou investigar uma faixa etária específica destes agressores, mas sim se os mesmos costumam ser mais novos, mais velhos ou da mesma idade que as vítimas. Neste sentido, $65 \%$ dos estudantes afirmaram que os agressores costumam ser mais velhos do que o colega que sofre a agressão. No que tange ao sexo dos agressores, $73 \%$ dos respondentes afirmaram que tanto os meninos como as meninas costumam praticar bullying na escola, ao passo que $26 \%$ identificaram "apenas meninos" envolvidos em situações de bullying. A opção "apenas meninas" não foi identificada por nenhum dos respondentes da pesquisa.

\section{Características do Bullying, na Percep- ção dos Professores}

Todos os professores que compuseram a amostra afirmaram presenciar frequentemente práticas de bullying na escola. No que se refere ao conceito de bullying apresentado pelos professores, pode-se identificar que cinco dos seis respondentes mencionaram em suas definições que o termo se refere a uma violência. Alguns mencionaram tipos de violência específicos em seus conceitos, tais como violência psicológica, sendo citada por cinco professores; violência física, citada por quatro; violência verbal, citada por três, e, por fim, a violência gestual, citada por um professor.

Os sujeitos envolvidos neste tipo de violência também foram abordados nas definições apresentadas pelo grupo de professores. Dois professores, dos seis respondentes, fizeram menção ao bullying como um tipo de violência que ocorre entre alunos, sendo que um destes professores afirmou, ainda, que também pode ocorrer entre alunos e professores, assim como entre alunos e funcionários. Ademais, somente um professor versou em seu discurso a respeito do local onde costuma ocorrer este tipo de violência, citando a escola em sua resposta. Apenas um professor afirmou não ter nenhum conhecimento a respeito da terminologia.

Os tipos de bullying identificados pelos professores inquiridos puderam ser divididos em duas subcategorias, sendo elas "agredir diretamente" (comportamentos de agressão verbal e física) e "agredir indiretamente" (comportamentos de agressão moral/ psicológica/ manipulação social). Agressões diretas expressas de forma verbal, tais como xingamentos e apelidos, foram as únicas citadas por todos os respondentes. No que tange aos comportamentos diretos de agressão física, o "socar" foi identificado por dois professores e os comportamentos de enforcar, chutar, apanhar, derrubar e pegar foram identificados uma única vez cada um. Ademais, os comportamentos de agressão indireta citados pelos respondentes foram os de ameaçar coercitivamente, ter preconceito e humilhar, os quais também foram citados uma vez cada.

No que se refere aos locais onde as práticas de bullying costumam ser manifestadas, a maioria dos professores identificou a "sala de aula", sendo citada por quatro respondentes. Dois docentes identificaram o "pátio da escola", dois 
afirmaram ocorrer em "todos os espaços escolares" e um professor também salientou a ocorrência de práticas de violência nos corredores da escola.

Os professores, assim como os estudantes, também identificaram os alunos mais velhos como autores de bullying. De acordo com três professores que compuseram a amostra, os alunos que costumam praticar o bullying são aqueles que destoam da faixa etária do restante da turma, tal como afirma P1: "O grande problema, normalmente, é nas turmas de quinta série e sexta, que a gente tem alunos com idade avançada e estão no meio dos pequenos. Então, eles se fazem ter respeito pela força". Os professores entrevistados também mencionaram que os autores de bullying costumam apresentar comportamentos competitivos, tais como atrapalhar na sala de aula para se sobressair perante a turma, se envolver em relações de competição por namorado(a) ou esportes e ser "folgado" com os demais. Dois professores apontaram, como característica comum entre os alunos que costumam praticar bullying na escola, a "falta de estrutura familiar"; dois apontaram que estes alunos têm pais agressivos e um afirmou que o relacionamento entre os pais é conflituoso. Um professor também apontou a condição de viver em um bairro violento como característica comum entre estes alunos.

Outro aspecto identificado pelos professores investigados relaciona os alunos que praticam atos de bullying com problemas de aprendizagem na escola. De acordo com três professores que compuseram a amostra, estes alunos costumam apresentar dificuldades de aprendizagem. Um dos professores apontou que os autores de bullying costumam ser alunos repetentes. Os professores entrevistados destacaram também, como características dos sujeitos que provocam bullying, a ocorrência de sentimentos positivos atrelados às agressões realizadas. Um professor citou que estes alunos sentem prazer em agredir os demais e outro citou que os mesmos sentem-se felizes ao praticar uma agressão. Apenas um professor alegou não saber identificar as características dos agressores.
Pode-se perceber, através dos resultados obtidos, que, além de abordarem características das vítimas de bullying em suas respostas, os professores investigados também versaram sobre motivos que acreditam levar à ocorrência deste fenômeno, bem como características desenvolvidas após contínua exposição ao fenômeno. No que se refere às respostas que envolviam uma explicação para a ocorrência do bullying, as mesmas foram divididas em três subcategorias: as causas familiares, sociais e emocionais.

No que tange às causas familiares, um professor citou a falta de estrutura familiar das vítimas e outro citou que estas crianças, além de sofrerem violência na escola, também costumam sofrer violência em casa. Já em relação às causas sociais, um professor citou que as crianças vítimas de bullying na escola costumam ser aquelas que já apresentam atritos com colegas fora da escola, perpetuando esta violência dentro do espaço escolar. Outro motivo apontado por quatro professores investigados foi que as vítimas costumam apresentar características que fogem do padrão socialmente compartilhado, sendo que dois professores citaram dentre estes aspectos a cor da pele, ou seja, que crianças negras costumam sofrer preconceito; dois citaram o fato de a vítima estar fora do peso; dois versaram sobre questões de gênero, alegando que meninos com trejeitos afeminados costumam ser vítimas de bullying, e um citou como característica o nível socioeconômico da vítima, afirmando que crianças com condições financeiras inferiores às demais costumam sofrer violência.

Apenas um professor citou em sua resposta aspectos emocionais das vítimas, afirmando que estas apresentam insegurança emocional, baixa autoestima, são ansiosas, sentem-se rejeitadas e "diminuídas" pela turma. Um dos professores entrevistados também apontou que estes alunos vivem se queixando na direção.

Ainda no que se refere às características dos alunos envolvidos em práticas de bullying, dois professores entrevistados afirmaram não conseguir identificar estudantes que são somente vítimas ou somente agressores. Para estes professores, os alunos que são vítimas de bullying 
também são aqueles que costumam agredir os demais. Como características destes alunos que são vítimas agressoras, um dos professores citou que tais crianças experimentam uma inversão ou falta de valores em sua criação. Também foi apontada por um dos professores, como característica das vítimas agressoras, pertencer a uma família que não se responsabiliza pela educação dos filhos.

\section{Discussão}

Os resultados obtidos no presente estudo, assim como os apresentados em pesquisas de grande abrangência realizadas em âmbito nacional (Fante \& Pedra, 2008; Fischer, 2010; Lopes, 2005; Lopes et al., n.d; Malta et al., 2010), apontam dados alarmantes acerca do bullying no contexto pedagógico brasileiro. É significativa a frequência de alunos e professores que parecem ter presenciado comportamentos agressivos entre estudantes na escola. Isto denota que a escola, ambiente que deveria ser um espaço de desenvolvimento e aprendizagem, também pode se caracterizar como um ambiente violento, onde se manifestam atitudes agressivas que provocam consequências extremas para os envolvidos $(\mathrm{Ca}-$ tini, 2004; Lopes, 2005).

Nesta pesquisa foi possível observar que os professores investigados apresentam uma definição restrita do fenômeno bullying, que se estreita em um "tipo de violência". Em suas definições, os educadores não utilizam critérios que diferenciem o bullying dos demais tipos de violência. Aspectos utilizados na literatura para caracterizar o fenômeno, tais como intencionalidade, repetição e desequilíbrio de poder são raramente citados pelos professores entrevistados. Isto pode estar atrelado à dificuldade de aferir objetivamente estes critérios, conforme aponta Fischer (2010).

Outra fragilidade percebida na conceituação de bullying por parte dos professores diz respeito aos sujeitos envolvidos neste tipo de violência. Os entrevistados não têm uma definição clara quanto a estes atos ocorrerem entre alunos, alunos e professores ou até mesmo entre alunos e funcionários.
Isto pode ser uma decorrência de o termo ser amplamente divulgado como um tipo de violência entre pares, abrindo espaço para diferentes interpretações sobre o que define "pares". Na literatura é possível encontrar diferentes definições no que tange aos envolvidos em práticas de bullying. Segundo Nogueira (2005), o bullying ocorre entre jovens e crianças. Piedra, Lago e Massa (2006) estreitam ainda mais esta definição, alegando que estas práticas ocorrem entre indivíduos em idade escolar. Já para Middelton-Moz e Zawadski (2007), o bullying pode ser uma prática executada também entre colegas de trabalho. Contudo, o bullying é caracterizado como um fenômeno que ocorre entre crianças e adolescentes, de forma intencional, repetitiva e sem motivação aparente, demarcado pelo desequilíbrio de poder e ausência de reciprocidade (Fante \& Pedra, 2008; Lisboa, 2005; Lisboa et al., 2009; Olweus, 2006).

Em relação às práticas de bullying, é possível observar que tanto alunos como professores identificam com mais facilidade comportamentos diretos, tais como empurrões, chutes, socos e agressões verbais, do que comportamentos indiretos, como isolar, difamar ou excluir. Também pode-se constatar que os professores identificam com maior frequência os comportamentos de bullying verbal do que físico ou psicológico, o que pode estar amparado no fato de os professores terem mais acesso aos alunos dentro da sala de aula, espaço onde estes dois últimos tipos de violência costumam ocorrer com menor frequência, em decorrência da supervisão do professor. Tais resultados corroboram dados encontrados em pesquisas realizadas anteriormente (Bandeira \& Hutz, 2012; Fekkes et al., 2005; Moura, Cruz, \& Quevedo, 2011), as quais apontam que comportamentos de maus-tratos verbais tendem a ser identificados com maior frequência do que comportamentos de maus-tratos físicos, bem como comportamentos diretos são identificados mais facilmente por serem mais visíveis do que comportamentos considerados indiretos (Bulach, Fulbright, \& Williams, 2003; Naylor, Cowie, Cossin, Bettencourt, \& Lemme, 2006; Olweus, 2006). Todavia, embora a violência psicológica seja menos discutida do que os outros tipos de 
violência que se manifestam no ambiente escolar, também resulta em consequências graves para os envolvidos (Catini, 2004; Crick \& Grotpeter, 1995).

Para os estudantes que participaram deste estudo, o local onde os comportamentos agressivos costumam ocorrer com maior frequência é na rua, indo ou voltando da escola. Tal dado vai ao encontro dos resultados obtidos por Catini (2004), em uma pesquisa que buscava identificar a natureza das experiências de bullying vivenciadas por crianças e adolescentes em um município paulistano. De acordo com a autora, os episódios de bullying relatados pelos participantes costumam ocorrer com maior frequência na saída da escola e tendem a envolver situações de violência física e ações de grupos. Já os professores do presente estudo não identificaram a rua como local propício para estas práticas, pois em sua grande maioria os mesmos passam a ter contato com os alunos apenas no interior da escola, fugindo à percepção destes o que ocorre fora dos muros deste ambiente.

Porém, tanto estudantes como professores identificaram o pátio e a sala de aula como outros locais onde costumam ocorrer comportamentos de bullying. Tais dados corroboram os resultados obtidos por pesquisas realizadas internacionalmente, as quais apontam o pátio de recreio como o lugar de maior incidência dos ataques de bullying (Fekkes et al., 2005; Scheithauer, Hayer, Petermann, \& Jugert, 2006). Entretanto, no Brasil as pesquisas apontam que o local onde mais ocorre bullying é a sala de aula (Fante \& Pedra, 2008; Francisco \& Libório, 2009; Lopes, 2005).

No que se refere às características dos alunos envolvidos em práticas de bullying, pode-se afirmar que estes possuem aspectos comuns. Tanto para os professores quanto para os alunos investigados nesta pesquisa, os estudantes que costumam ser autores de bullying são, geralmente, de ambos os sexos. Embora a maioria da amostra (73\%) tenha referenciado que tanto meninos como meninas costumam ser autores de bullying na escola, torna-se significativo o índice de alunos que afirmaram que apenas meninos costumam se envolver nestas práticas $(26 \%)$, ao passo que nenhum respondente associou apenas as meninas como autoras.

Neste sentido, muitos estudos empíricos têm constatado maior incidência de bullying em meninos (Lisboa, 2005; Lopes et al., n.d.; Malta et al., 2010; Moura et al., 2011; Olweus, 2006). Contudo, pesquisadores contrastaram os resultados encontrados em determinadas investigações sobre agressão na infância, as quais tendem a apontar que os meninos são mais agressivos do que as meninas. Dentre estes, Crick e Grotpeter (1995) realizaram um estudo fundamentado na hipótese de que essa constatação reflete uma falta de pesquisas sobre formas de agressão que são relevantes para jovens do sexo feminino, ao invés de uma diferença real de gênero nos níveis de agressividade. Para estes pesquisadores, os meninos tendem a prejudicar os outros por meio de agressões físicas e verbais, comportamentos consistentes com os tipos de objetivos importantes para os meninos dentro de seus grupos, tais como instrumentalidade e domínio físico. Já as meninas são mais propensas a se concentrar em questões relacionais durante a interação e buscam agredir os demais através de agressões indiretas (isto é, ferir os colegas através da manipulação social, causar danos em suas relações com seus pares; Crick \& Groetpeter, 1995). Por conseguinte, pesquisas que buscam relacionar a incidência de determinadas formas de expressão de violência com os gêneros têm identificado que tanto meninos quanto meninas tendem a se envolver em práticas de bullying, o que difere é o tipo de agressão - meninos tendem a se envolver com maior frequência em comportamentos diretos, ao passo que meninas tendem a estar associadas a práticas indiretas (Björkqvist, Österman, \& Kaulkiainen, 1992; Borsa, 2012; Crick \& Grotpeter, 1995; Lisboa, 2005).

Professores e alunos também concordaram ao caracterizar os alunos autores de bullying como mais velhos do que suas vítimas e que utilizam sua força física para amedrontar os colegas.

De acordo com pesquisas realizadas por Olweus (2006), parece haver uma associação entre força física e popularidade na escola, sendo que os alunos que possuem maior força física 
também apresentam maior nível de popularidade entre os colegas, assim como o inverso. Deste modo, os alunos maiores ou mais fortes que costumam se comportar de forma agressiva entre os colegas tendem a atrair a atenção de seus pares, pois as outras crianças percebem que eles têm poder e são respeitados por isso (Beane, 2010; Hawley \& Vaughn, 2003). Isto vai ao encontro dos resultados encontrados por Pellegrini e Bartini (2001), em um estudo longitudinal que buscou examinar as mudanças no desenvolvimento da dominância e agressão em meninos que estão em transição da escola primária para a escola secundária. Os autores identificaram que a dominância diminuiu na medida em que os meninos fizeram a transição de uma instituição em que eram os mais velhos e fisicamente maiores para outra em que eram os mais jovens e menores. Consequentemente, o status - incluindo a dominância - precisou ser redefinido ao mesmo tempo que o estabelecimento de novas relações entre pares foi particularmente importante. Tais resultados permitem concluir que idade e estatura física tendem a ser aspectos preditores de dominância social, conferindo aos alunos mais velhos e fisicamente mais fortes um status perante o grupo de pares.

Outra característica dos alunos agressores identificada pelos professores participantes foi que estes alunos provêm de "famílias desestruturadas", cujos pais são violentos ou apresentam relacionamentos conflituosos. Tais características corroboram resultados encontrados em outras pesquisas acerca das práticas de violência entre pares e/ou bullying nas escolas, as quais relacionam famílias menos coesas e mais conflituosas com o surgimento de comportamentos agressivos na infância (Fischer, 2010; Lobato \& Placco, 2007; Stevens, Bourdeaudhuij, \& Van Oost, 2002). Por outro lado, a ênfase dos docentes nas causas exógenas à escola em detrimento das variáveis endógenas parece ser mais conveniente para os professores e para a instituição escolar como um todo, visto que permite a estes a retirada de sua parcela de responsabilidade na produção de violência (Lobato \& Placco, 2007).
Vale destacar ainda que, segundo os professores entrevistados, os alunos que são vítimas de bullying também apresentam características em comum. Geralmente são menores do que os agressores e apresentam comportamentos e/ou aspectos físicos (relacionados ao vestuário, estatura, peso, cor da pele) que destoam da maior parte do grupo (Catini, 2004; Lisboa et al., 2009; Moura et al., 2011). Parece existir uma dinâmica de homogeneidade, a qual é instituída a priori entre os membros do grupo (Lisboa et al., 2009). Estes grupos tornam-se exclusivos e impermeáveis a outros que possam descaracterizar a estrutura grupal, possibilitando um clima que favorece ou desfavorece características particulares dos indivíduos e pode fazer com que uma criança seja menos ou mais popular (Chang, 2004). As características desviantes desempenham um papel importante na origem dos problemas entre agressores e vítimas, especialmente na colocação de apelidos, visto que muitas vezes estes são revestidos de discriminações e preconceitos que podem contribuir com uma autoimagem negativa e, deste modo, tornar as vítimas ainda mais vulneráveis (Catini, 2004).

Para um dos professores participantes deste estudo, as vítimas costumam apresentar insegurança emocional, baixa autoestima, sentem-se rejeitadas e diminuídas pelo restante da turma. Entretanto, conforme aponta Lisboa (2005), é difícil definir se estas características são antecedentes ou consequências de maus-tratos. Por este motivo, a autora afirma que é importante que as conclusões teóricas e os dados empíricos não venham a legitimar a violência entre pares baseando-se nas características individuais como forma de justificativa para tal.

Ainda no que se refere às características dos alunos envolvidos em práticas de bullying, os resultados da pesquisa apontam para a existência de estudantes que não são somente vítimas ou somente agressores, mas sim alunos que são agredidos e agridem os demais. Em pesquisa realizada por Moura et al. (2011), os autores identificaram que $47 \%$ das vítimas também provocam bullying. Tais alunos, segundo Fante e Pedra (2008), são vítimas agressoras que foram 
vitimizadas e acabam reproduzindo os maus-tratos sofridos. Deste modo, integram-se a grupos para hostilizar seu agressor ou elegem outra vítima como bode-expiatório.

Entretanto, Schultz et al. (2012), sob o enfoque da Teoria Bioecológica do Desenvolvimento Humano, enfatizam a necessidade de perceber o bullying como um fenômeno relacional, influenciado por vários indivíduos e sistemas, não sendo possível reduzi-lo à dualidade agressor/ vítima. Neste sentido, as decorrências deste fenômeno atingem também as testemunhas, a escola e a comunidade como um todo, perpetuando a violência nos diferentes contextos sociais.

\section{Considerações Finais}

Pensar o bullying no ambiente escolar é uma questão urgente. Suas vicissitudes se alastram sob os olhos de pais, educadores e legisladores, os quais, em sua grande maioria, não sabem intervir e/ou prevenir a ocorrência desse fenômeno (Catini, 2004; Fekkes et al., 2005). A falta de intervenção dos responsáveis diante das manifestações de bullying na escola parece contribuir para que essas práticas continuem a se reproduzir neste espaço e para que atinjam cada vez mais os estudantes.

$\mathrm{Na}$ presente pesquisa, pode-se perceber que cerca de $94 \%$ dos estudantes já presenciaram comportamentos agressivos ocorrendo na escola, sendo que aproximadamente $54 \%$ deles presenciaram a ocorrência de bullying. No que tange aos professores, todos eles afirmaram já ter presenciado esse tipo de fenômeno quase que diariamente na escola, especialmente na forma de agressões diretas expressas verbalmente. Pesquisas de levantamento que visem caracterizar o bullying nas escolas parecem ser relevantes como ponto de partida para que esse tipo de fenômeno possa ser combatido e prevenido. Neste estudo, visava-se realizar um censo sobre as características do bullying na escola. No entanto, foi possível realizá-lo a partir de uma amostra de 83 estudantes, haja vista as dificuldades em obter autorização dos responsáveis legais de todos os estudantes. Dessa forma, ainda que os dados obtidos possibilitem caracterizar vários aspectos do fenômeno investigado, não permitem que os mesmos sejam generalizados para a população de estudantes. Da mesma maneira, a frequência de ocorrência de cada tipo de comportamento de bullying, tanto do ponto de vista de professores como de alunos, poderia ter sido investigada para caracterizar de forma ainda mais precisa esse tipo de fenômeno no ambiente escolar examinado.

A partir dos resultados obtidos, pode-se concluir que ainda há muito a ser feito para reduzir a incidência do bullying nas escolas. Em grande parte dos estudos realizados sobre este tipo de violência, identificam-se práticas de bullying mais facilmente observadas, tais como agressões físicas e verbais (Bulach et al., 2003; Naylor et al., 2006; Olweus, 2006). Entretanto, práticas mais sutis, que se tornam mais difíceis de ser aferidas por professores e colegas, ainda passam despercebidas pela maioria das pessoas. Pelo fato de não serem combatidas, comumente são as que causam danos mais sérios.

Faz-se necessário refletir também acerca de políticas públicas adequadas à realidade do ambiente pedagógico brasileiro, as quais podem dar origem a ações de promoção de um ambiente sadio de desenvolvimento e aprendizagem nas escolas. Investir também na capacitação de professores e dos gestores das escolas para que possam reconhecer e intervir mais diretamente sobre as ocorrências de bullying - uma vez que a sala de aula parece ainda ser um dos locais em que esse tipo de fenômeno mais ocorre - é fundamental como forma de tornar a escola, de fato, um espaço mais saudável para o desenvolvimento de crianças e jovens.

Prosseguir com a realização de estudos que busquem sistematizar informações sobre o conceito de bullying e sobre os critérios que o diferenciam dos demais tipos de violência ocorridos no ambiente escolar também parece ser promissor para desmistificar cada vez mais esta temática. Deste modo, é possível caracterizar as especificidades do fenômeno em questão e distingui-lo de práticas e brincadeiras infanto-juvenis. Pesquisas referentes às consequências do bullying 
para os envolvidos direta ou indiretamente com esse tipo de fenômeno, assim como às formas e à eficácia das intervenções que têm sido realizadas no ambiente escolar também parecem ser promissoras. Esses parecem ser trabalhos que, ainda que não prometam a "erradicação do bullying nas escolas", sinalizam a possibilidade de algumas mudanças tão urgentes e necessárias nesse contexto.

\section{Referências}

Bandeira, C. M., \& Hutz, C. S. (2012). Bullying: Prevalência, implicações e diferenças entre os gêneros. Revista Semestral da Associação Brasileira de Psicologia Escolar e Educacional, 16(1), 35-44.

Bardin, L. (2011). Análise de conteúdo (L. A. Reto \& A. Pinheiro, Trads.). São Paulo, SP: Edições 70. (Trabalho original publicado em 1977)

Beane, A. L. (2010). Proteja seu filho do bullying. Rio de Janeiro, RJ: BestSeller.

Björkqvist, K., Österman, K., \& Kaukiainen, A. (1992). Social intelligence - Empathy $=$ Agression? Agression and Violent Behavior, 5, 191200.

Borsa, J. C. (2012). Adaptação e validação transcultural do Questionário de Comportamentos Agressivos e Reativos entre Pares (Q-CARP) (Tese de doutorado, Programa de Pós-Graduação em Psicologia, Universidade Federal do Rio Grande do Sul, Porto Alegre, RS, Brasil).

Bulach, C., Fulbright, J. P., \& Williams, R. (2003). Bullying behavior: What is the potential for violence at your school? Journal of Instructional Psychology, 10(2), 156-164.

Carvalhosa, S. F., Lima, L., \& Matos, M. G. (2001). Bullying: A provocação/vitimação entre pares no contexto escolar português. Análise Psicológica, 20(4), 523-537.

Catini, N. (2004). Problematizando o "bullying" para a realidade brasileira (Tese de doutorado, Programa de Pós-Graduação em Psicologia, Centro de Ciências da Vida, Pontifícia Universidade Católica de Campinas, Campinas, SP, Brasil).

Chang, L. (2004). The role of classroom norms in contextualizing the relations of children's social behaviors to peer acceptance. Developmental Psychology, 40, 691-702.
Crick, N. R., \& Grotpeter, J. K. (1995). Relational aggression, gender, and social-psychological adjustment. Child Development, 66(3), 710-722.

Cubas, V. O. (2006). Bullying: Assédio moral na escola. In C. Ruotti, R. Alves, \& V. O. Cubas, Violência na escola: Um guia para pais e professores (pp. 175-206). São Paulo, SP: Andhep - Imprensa Oficial do Estado de São Paulo.

Duque, D. (2007). Bullying: A violência invisível. Revista Dimensão, 49, 24-25.

Fante, C., \& Pedra, J. A. (2008). Bullying escolar: Perguntas e respostas. Porto Alegre, RS: Artmed.

Fekkes, M., Pijpers, F. I. M., \& Verloove-Vanhorick, S. P. (2005). Bullying: Who does, what, when and where? Involvement of children, teachers and parents in bullying behavior. Health Education Research, 20(1), 81-91.

Fischer, R. M. (Coord.). (2010). Bullying escolar no Brasil: Relatório final. São Paulo, SP: Centro de Empreendedorismo Social e Administração em Terceiro Setor, Fundação Instituto de Administração.

Flores, C. A. (2007). Bullying em contexto escolar: O que os educadores sabem sobre o fenômeno? (Monografia de graduação em Psicologia, Universidade do Vale do Itajaí, Itajaí, SC, Brasil).

Francisco, M. V., \& Libório, R. M. C. (2009). Um estudo sobre bullying entre escolares do ensino fundamental. Psicologia: Reflexão e crítica, 22(2), 200-207.

Gil, A. C. (1999). Métodos e técnicas de pesquisa social (5. ed.). São Paulo, SP: Atlas.

Hamilton, L. D., Newman, M. L., Delville, C. L., \& Delville, Y. (2008). Physiological stress response of young adults exposed to bullying during adolescence. Physiology \& Behavior, 95(5), 617-624.

Hawley, P. H., \& Vaughn, B. E. (2003). Agression and adaptative functioning: The bright side to bad behavior. Merril-Palmer Quaterly, 49(3), 239-244.

Krug, E. G., Dahlberg, L. L., Mercy, J. A., Zwi, A. B., \& Lozano, R. (2002). World report on violence and health. Geneva, Switzerland: World Health Organization.

Lisboa, C. S. M. (2005). Comportamento agressivo, vitimização e relações de amizade em crianças em idade escolar: Fatores de risco e proteção 
(Tese de doutorado, Programa de Pós-Graduação em Psicologia do Desenvolvimento, Universidade Federal do Rio Grande do Sul, Porto Alegre, RS, Brasil).

Lisboa, C. S. M., Braga, L. L., \& Ebert, G. (2009). O fenômeno bullying ou vitimização entre pares na atualidade: Definições, formas de manifestação e possibilidades de intervenção. Contextos Clínicos, 2(1), 59-71.

Lobato, V. S., \& Placco, V. M. N. S. (2007). Concepções de professores sobre questões relacionadas à violência na escola. Psicologia da Educação, 24, 73-90.

Lopes, A. A., Neto (2005). Bullying - Comportamento agressivo entre estudantes. Jornal de Pediatria, 81(05), 164-172.

Lopes, A. A., Neto, Monteiro, L., Filho, \& Saavedra, L. H. (Coords.). (n.d.). Programa de Redução de Comportamentos Agressivos entre Estudantes. Rio de Janeiro, RJ: Associação Brasileira Multiprofissional de Proteção à Infância e à Adolescência.

Malta, D. C., Silva, M. A. I., Mello, F. C. M., Monteiro, R. A., Sardinha, L. M. V., Crespo, C., ...Porto, D. L. (2010). Bullying nas escolas brasileiras: Resultados da Pesquisa Nacional de Saúde do Escolar (PeNSE), 2009. Ciência \& Saúde Coletiva, 15(2), 3065-3076.

McLaughlin, J., \& Miller, T. (2008). Prevention of school violence: Directions, summary and conclusions. In T. Miller (Ed.), School violence and primary prevention (pp. 431-444). New York: Springer.

Middelton-Moz, J., \& Zawadsky, M. L. (2007). Bullying: Estratégias de sobrevivência para crianças e adultos. Porto Alegre, RS: Artmed.

Moura, D. R., Cruz, A. C. N., \& Quevedo, L. A. (2011). Prevalência e características de escolares vítimas de bullying. Jornal de Pediatria, 1(87), 19-23.

Naylor, P., Cowie, H., Cossin, F., Bettencourt, R., \& Lemme, F. (2006). Teachers' and pupils' definitions of bullying. British Journal of Educational Psychology, 76, 553-576.

Nogueira, R. M. C. P. A. (2005). A prática de violência entre pares: O bullying nas escolas. Revista Iberoamericana de Educación, 37, 93-102.

Olweus, D. (2006). Bullying at school: What we know and what we can do. Oxford, UK: Blackwell.
Pellegrini, A. D., \& Bartini, M. (2001). Dominance in early adolescent boys: Affiliative and aggressive dimensions and possible functions. Merrill-Palmer Quarterly, 47(1), 142-163.

Piedra, R. R., Lago, A. S., \& Massa, J. L. P. (2006). Crianças contra crianças: O bullying, uma perturbação emergente. Anales de Pediatria, 1(2), 101-104.

Rigby, K. (2003). Consequences of bullying in schools. The Canadian Journal of Psychiatry, 48(9), 583-590.

Salmivalli, C., Lagerspetz, K. M. J., Björkqvist, K., Österman, K., \& Kaukianen, A. (1996). Bullying as a group process: Participation roles and their relations to social status within the group. Aggressive Behavior, 22, 1-15.

Salmon, G., James, A., \& Smith, D. M. (1998). Bullying in schools: Reported anxiety, depression and self-esteem in secondary school children. British Medical Journal, 317, 924-925.

Scheithauer, H., Hayer, T., Petermann, F., \& Jugert, G. (2006). Physical, verbal, and relational forms of bullying among german students: Age trends, gender differences, and correlates. Aggressive Behavior, 32(3), 261-275.

Schultz, N. C. W., Duque, D. F., Silva, C. F., Souza, C. D., Assini, L. C., \& Carneiro, M. G. M. (2012). A compreensão sistêmica do bullying. Psicologia em Estudo, 17(2), 247-254.

Silva, A. B. B. (2010). Bullying: Mentes perigosas nas escolas. Rio de Janeiro, RJ: Objetiva.

Smith, P. K., Cowie, H., Olafsson, R. F., \& Liefooghe, A. P. D. (2002). Definitions of bullying: A comparison of terms used, and age and gender differences, in a fourteen-country international comparison. Child Development, 73(4), 11191133.

Stattin, H., \& Magnusson, D. (1989). The role of early aggressive behavior in the frequency, seriousness, and types of later crimes. Journal of Consulting and Clinical Psychology, 57(6), 710718.

Stevens, V., Bourdeaudhuij, L., \& Van Oost, P. (2002). Relationship of the family environment to children's involvement in bully/victim problems at school. Journal of Youth and Adolescence, 31(6), 419-429.

Van der Wal, M. F., Wit, C. A. M., \& Hirasing R. A. (2003). Psychosocial health among young vic- 
tims and offenders of direct and indirect bullying. Pediatrics, 111(16), 1312-1318.

Veiga, A. (2004). Sutil e Cruel Agressão. Revista Época, 315, 54-61.

Vieira, T. M., Mendes, F. D. C., \& Guimarães, L. C. (2009). De Columbine à Virgínia Tech: Reflexões com base empírica sobre um fenômeno em expansão. Psicologia: Reflexão e Crítica, 22(3), 493-501.

Wendt, G. W., Campos, D. M., \& Lisboa, C. S. M. (2010). Agressão entre pares e vitimização no contexto escolar: Bullying, cyberbullying e os desafios para a educação contemporânea. $\mathrm{Ca}$ dernos de Psicopedagogia, 8(14), 41-52.
Zaine, I., Reis, M. J. D., \& Padovani, R. C. (2010). Comportamentos de bullying e conflitos com a lei. Estudos de Psicologia (Campinas), 27(3), 375-382.

Recebido: 06/06/2013

$1^{a}$ revisão: $14 / 08 / 2013$

$2^{a}$ revisão: $12 / 09 / 2013$

Aceite final: 25/09/2013 